\title{
The Effect of Protonated Ethionine Adsorption on Bi(III) Electroreduction in Chlorate(VII) Solutions with Varied Water Activity
}

\author{
Agnieszka Nosal-Wiercińska ${ }^{1} \cdot$ Mariusz Grochowski $^{1}$
}

Published online: 7 February 2018

(C) The Author(s) 2018. This article is an open access publication

\begin{abstract}
The Bi(III) electroreduction in the presence of the ethionine (Et) was studied under its different protonation and changes of water activity. In order to determine adsorption and kinetic parameters, the following were applied: DC polarography, square wave voltammetry (SWV), cyclic voltammetry (CV), and electrochemical impedance spectroscopy (EIS). The influence of ethionine on the double-layer parameters at the electrode/chlorate (VII) interface and multistep Bi(III) ion electroreduction was found. The multistep $\mathrm{Bi}$ (III) electroreduction process is controlled by the kinetics of the formation of active Bi-Et complexes on the electrode surface. The size of the catalytic effect is connected with the equilibrium of the reaction creating active complexes before the successive transition of electrons.
\end{abstract}

Keywords Bi(III) electroreduction $\cdot$ Ethionine $\cdot$ Adsorption $\cdot$ Active complexes $\cdot$ Kinetic parameters $\cdot$ Water activity

\section{Introduction}

The knowledge of the organic substance effect on the electrode reaction rate is of significant importance in the analytics as well as elaboration of technological and pharmacological characteristics. Organic substances can inhibit [1-4] and accelerate the electrode process [5-11] or not affect its course. It was found that an essential role in the electrode process acceleration is played by the ability of organic substance, undergoing adsorption on the electrode, to form complexes with the depolarizer in the circum electrode layer and location of the depolarizer reduction potential in the area of labile adsorption equilibrium of the organic substance [7, 12]. The previous studies proved a significant effect of water activity [13], some amino acids [14-17], and change of the protonation of the amino acids on mechanism and kinetics of Bi(III) ions electroreduction [18-21], which developed the interpretation of the "cap-pair" effect mechanism [11].

Agnieszka Nosal-Wiercińska

anosal@poczta.umcs.lublin.pl

1 Department of Analytical Chemistry and Instrumental Analysis, Faculty of Chemistry, M. Curie-Skłodowska University, M. Curie-Skłodowska Sq. 3, 20-031 Lublin, Poland
It was concluded that the presence and the protonation of ethionine affect the rate of the multistep process of $\mathrm{Bi}(\mathrm{III})$ electroreduction in $2 \mathrm{~mol} \mathrm{dm}^{-3}$ chlorates (VII) [21]. The mechanism of the catalytic effect of ethionine is associated with the formation of complexes under specific conditions existing on the electrode surface. Ethionine adsorption favors formation of these complexes. Changes of adsorption parameters at the $\mathrm{Hg} /$ chlorate (VII) interfaces are affected by the total charge of the adsorbate molecule which is a result of $\mathrm{pH}$ solution [21-23].

Ethionine plays an important role in maintaining of homeostasis in living organism. It proves that even a slight difference in the amino acid structure (the presence of one inactive group$\mathrm{CH}_{2}$; Scheme 1) can result in an antagonistic effect on the living organism. Ethionine has a very destructive influence on the livers of living organisms and disrupts the activity of many enzymes. It is a strongly carcinogenic metabolite contributing to the development of most types of human cancer [24-27].

The presented investigations have an essential practical aspect. The knowledge about electrochemical properties of amino acids is an important pharmaceutical tool because it can be indispensable to understand their metabolic path or the redox processes occurring "in vivo." The results of the investigations can be a scientific basis for elaboration of electroanalytical methods of their determination as well as understanding the mechanism of their action in the organism. Based on the above, carrying on the studies of kinetics and mechanism of 
<smiles>CCC1CCCCC1</smiles>

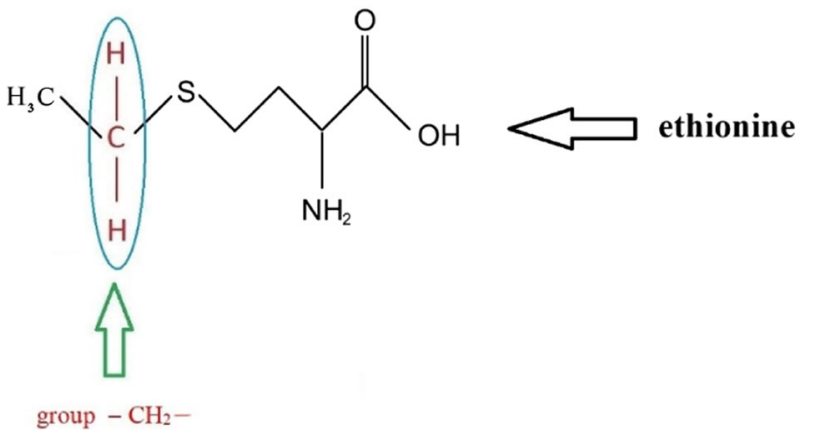

Scheme 1 Structural formulas of the methionine and ethionine

$\mathrm{Bi}(\mathrm{III})$ ion electroreduction in the presence of ethionine under the conditions of its various protonation and water activity seems to be justified.

The methodology of the study is based on the electrochemical methods: DC polarography, square wave voltammetry (SWV), cyclic voltammetry (CV), and electrochemical impedance spectroscopy (EIS). The applied methods indicate the extent of ethionine catalytic effect. The determined adsorption and kinetic parameters are correlated with the changes of amino acid protonation and water activity.

\section{Experimental}

\section{Chemicals}

The 2, 4, and $6 \mathrm{~mol} \mathrm{dm}^{-3}$ chlorate (VII) solutions of the $\mathrm{HClO}_{4} / \mathrm{NaClO}_{4}$ concentration ratios: (1:1) solution $\mathrm{A}$, (1:4) solution B, (1:9) solution C, (4:1) solution D, and (9:1) solution $\mathrm{E}$ were examined. The concentration of $\mathrm{Bi}(\mathrm{III})$ ions in the studied solutions was always $1 \times 10^{-3} \mathrm{~mol} \mathrm{dm}{ }^{-3}$. The solutions were sonicated due to the weak solubility of $\mathrm{Bi}\left(\mathrm{NO}_{3}\right)_{3}$ in chlorate (VII). The ethionine solutions $\left(5 \times 10^{-4}, 1 \times 10^{-3}\right.$, and $3 \times 10^{-3} \mathrm{~mol} \mathrm{dm}^{-3}$ ) were prepared just before the measurements. Analytical-grade chemicals from Fluka were used. Water applied to prepare all solutions was purified in the Millipore system.

\section{Methods}

All electrochemical measurements were carried out with a $\mu$ Autolab Fra 2/ GPES (version 4.9) analyzer (Eco Chemie, Utrecht, Netherlands). The working electrode was a dropping or hanging mercury-electrode with a controlled increase rate and a constant drop surface $\left(0.0116241 \mathrm{~cm}^{2}\right)$. It was made by MTM, Poland. The reference electrode was a silver chloride electrode and the auxiliary electrode was platinum.

In the DC polarography, SWV, and CV voltammetry, the optimal experiment operating conditions were as follows: step potential $2 \mathrm{mV}$ for DC; pulse amplitude $20 \mathrm{mV}$, frequency $120 \mathrm{~Hz}$, and step potential $2 \mathrm{mV}$ for the SWV; scan rate 5$1000 \mathrm{mV} \mathrm{s}^{-1}$ and step potential $5 \mathrm{mV}$ for the CV. The impedance data were collected at 26 frequencies in the range from 200 to $50,000 \mathrm{~Hz}$ within the faradaic potential region with $10 \mathrm{mV}$ intervals.

The details of the determination of the kinetic and adsorption parameters are described elsewhere $[13,28]$.

\section{Results and Discussion}

\section{Double-Layer Analysis}

A significant effect of ethionine on the changes of the parameters of the $\mathrm{Hg} /$ chlorate (VII) interface double layer was observed [21]. The course of the differential capacity curves on mercury in the chlorate (VII) solutions depends also on the changes in the $\mathrm{HClO}_{4} / \mathrm{NaClO}_{4}$ concentration ratio in the basic electrolyte and water activity (Fig. 1a).

The increased $\mathrm{NaClO}_{4}$ concentration in the $2 \mathrm{~mol} \mathrm{dm}^{-3}$ chlorate (VII) solutions increases the differential capacitance of the double layer in the area of the capacitance hump (from 0 up to $-1000 \mathrm{mV})$. The positive potential $(\approx 0 \mathrm{mV})$ at $C_{d}=f(E)$ curves shows adsorption peaks which increasing with the increase of $\mathrm{NaClO}_{4}$ concentration in the supporting electrolyte. The increase in the $\mathrm{HClO}_{4}$ concentration in the chlorate (VII) solutions (Fig. 1, curves D and E) results in a significant change in the height of the capacitance hump and peaks on the differential capacitance curves. The increased chloric (VII) acid concentration in the supporting electrolyte causes the decrease in the differential capacity (curves D and E). Similar changes probably associated with those of the electrostatic interactions between differently protonated amino acid molecules adsorbed on mercury were also observed for 4 and $6 \mathrm{~mol} \mathrm{dm}^{-3}$ chlorate (VII) solutions. On the other hand, the observed changes in the picture of capacity curves depending on the chlorate (VII) concentration (Fig. 1a) prove the competitive adsorption of ethionine molecules and $\mathrm{ClO}_{4}{ }^{-}$ions and indicate a significant effect of water molecules on the interface properties [28].

The values of potential of zero-charge $E_{z}$ collected in Table 1 point out to the fact that the addition of ethionine to chlorate (VII) has an effect on the shift of the $E_{z}$ values towards more negative potentials with the increasing concentration of amino acid which is characteristic of the adsorption of 


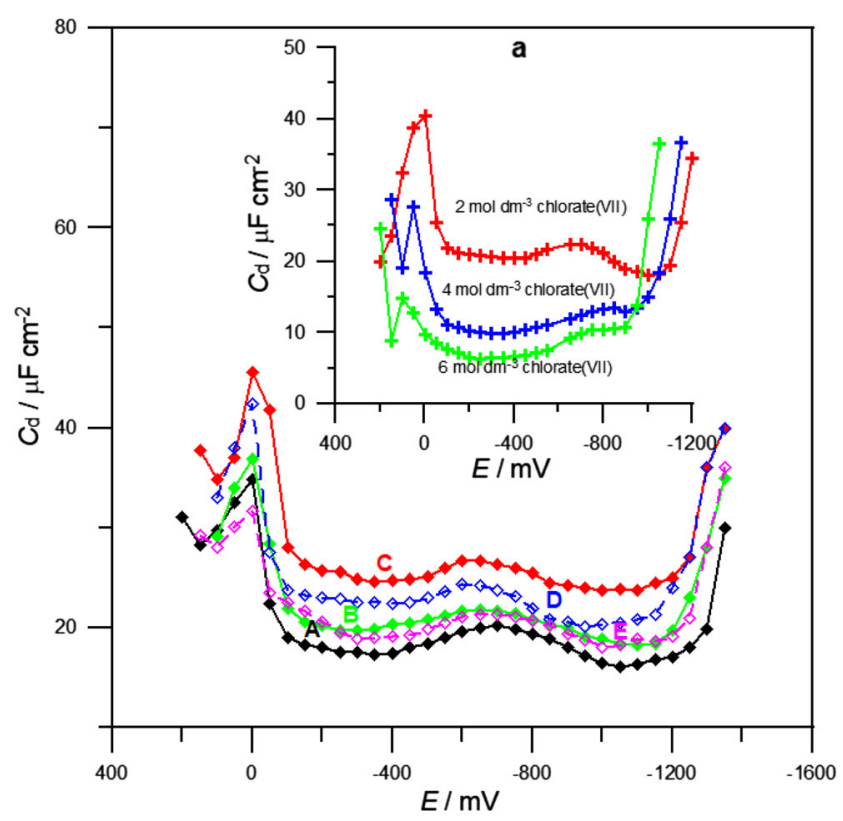

Fig. 1 Differential capacity-potential curves of double-layer interface $\mathrm{Hg}$ / $2 \mathrm{~mol} \mathrm{dm}^{-3}$ chlorate (VII) with $3 \times 10^{-3} \mathrm{~mol} \mathrm{dm}^{-3}$ ethionine, where $\mathrm{HClO}_{4} /$ $\mathrm{NaClO}_{4}=1: 1$ (black filled diamond) $2 \mathrm{~A} ; \mathrm{HClO}_{4} / \mathrm{NaClO}_{4}=1: 4$ (green filled diamond) $2 \mathrm{~B} ; \mathrm{HClO}_{4}: \mathrm{NaClO}_{4}=1: 9$ (red filled diamond) $2 \mathrm{C}$; $\mathrm{HClO}_{4}: \mathrm{NaClO}_{4}=4: 1$ (blue open diamond) 2D; $\mathrm{HClO}_{4}: \mathrm{NaClO}_{4}=9: 1$ (pink open diamond) 2E. a Differential capacity-potential curves of double-layer interface $\mathrm{Hg} / 2 \mathrm{~mol} \mathrm{dm}^{-3}$ chlorate (VII) (red cross), $4 \mathrm{~mol} \mathrm{dm}^{-3}$ chlorate (VII) (blue cross), and $6 \mathrm{~mol} \mathrm{dm}^{-3}$ chlorate (VII) (green cross) with $3 \times 10^{-3} \mathrm{~mol} \mathrm{dm}{ }^{-3}$ ethionine, where $\mathrm{HClO}_{4} / \mathrm{NaClO}_{4}=$ $4: 1$

anions [28-30]. Moreover, one can observe that the increase of $\mathrm{NaClO}_{4}$ concentration in the chlorate (VII) solution has the effect on the shift of $E_{z}$ values towards positive potentials, but the $\mathrm{HClO}_{4}$ concentration increases towards more negative potentials. These changes, depending on the ethionine protonation degree in the studied chlorate (VII) solution, point out to reorganization of amino acid molecules on electrode surface [19-21]. The linear dependences $E_{z}=f\left(\log c_{\text {ethionine }}\right)$, obtained for all studied concentrations of chlorate (VII), indicate the specific adsorption of the amino acid on the electrode surface [28].

As follows from Table 2, the addition of ethionine to 2, 4, and $6 \mathrm{~mol} \mathrm{dm}^{-3}$ chlorate (VII) solutions causes an insignificant drop of the surface tension at zero-charge potential $\gamma_{z}$. The greater the ethionine concentration in the supporting electrolyte solution is, the greater the changes are. The obtained results confirm ethionine adsorption on mercury [21].

\section{Kinetic Studies}

Increase of reversibility of $\mathrm{Bi}(\mathrm{III})$ ion electroreduction in the $2 \mathrm{~mol} \mathrm{dm}^{-3}$ chlorates (VII) in the presence of ethionine was proved [21]. The magnitude of this effect depends on the ethionine concentrations as well as changes in the $\mathrm{HClO}_{4} /$ $\mathrm{NaClO}_{4}$ ratio in the chlorate (VII) solutions. Similar
Table 1 Potential of zero-charge $\left(E_{z}\right) \mathrm{vs}$. $\mathrm{Ag} / \mathrm{AgCl}$ electrode of chlorate (VII) solutions of concentration ratio $\left(\mathrm{HClO}_{4} / \mathrm{NaClO}_{4}\right)$ : (1:1) solution A, (1:4) solution B, (1:9) solution C, (4:1) solution D, and (9:1) solution E + ethionine systems

\begin{tabular}{|c|c|c|c|c|}
\hline & \multicolumn{4}{|l|}{$-E_{z} / \mathrm{V}$} \\
\hline & 0 & $\begin{array}{l}5 \times 10^{4} \mathrm{c}_{\mathrm{Et}} / \\
\mathrm{mol} \mathrm{dm}\end{array}$ & $\begin{array}{l}1 \times 10^{3} \mathrm{c}_{\mathrm{Et}} / \\
\mathrm{mol} \mathrm{dm}\end{array}$ & $\begin{array}{l}3 \times 10^{3} \mathrm{c}_{\mathrm{Et}} / \\
\mathrm{mol} \mathrm{dm}\end{array}$ \\
\hline \multicolumn{5}{|l|}{$\mathrm{a}$} \\
\hline \multicolumn{5}{|c|}{$2 \mathrm{~mol} \mathrm{dm}^{-3}$ chlorate (VII) } \\
\hline $\mathrm{A}$ & 0.483 & 0.486 & 0.492 & 0.495 \\
\hline $\mathrm{B}$ & 0.481 & 0.485 & 0.487 & 0.492 \\
\hline $\mathrm{C}$ & 0.480 & 0.488 & 0.492 & 0.496 \\
\hline $\mathrm{D}$ & 0.494 & 0.505 & 0.509 & 0.511 \\
\hline $\mathrm{E}$ & 0.496 & 0.511 & 0.513 & 0.514 \\
\hline \multicolumn{5}{|l|}{$\mathrm{b}$} \\
\hline \multicolumn{5}{|c|}{$4 \mathrm{~mol} \mathrm{dm}^{-3}$ chlorate (VII) } \\
\hline A & 0.497 & 0.509 & 0.512 & 0.514 \\
\hline $\mathrm{B}$ & 0.496 & 0.506 & 0.507 & 0.508 \\
\hline $\mathrm{C}$ & 0.487 & 0.491 & 0.494 & 0.500 \\
\hline $\mathrm{D}$ & 0.536 & 0.538 & 0.539 & 0.540 \\
\hline $\mathrm{E}$ & 0.547 & 0.551 & 0.553 & 0.557 \\
\hline \multicolumn{5}{|l|}{$\mathrm{c}$} \\
\hline \multicolumn{5}{|c|}{$6 \mathrm{~mol} \mathrm{dm}^{-3}$ chlorate (VII) } \\
\hline $\mathrm{A}$ & 0.528 & 0.542 & 0.546 & 0.547 \\
\hline B & 0.522 & 0.536 & 0.537 & 0.538 \\
\hline $\mathrm{C}$ & 0.519 & 0.534 & 0.535 & 0.537 \\
\hline $\mathrm{D}$ & 0.581 & 0.583 & 0.586 & 0.588 \\
\hline $\mathrm{E}$ & 0.607 & 0.605 & 0.603 & 0.592 \\
\hline
\end{tabular}

dependences were observed in more concentrated chlorate (VII) solutions (Fig. 2). The SWV peaks of Bi(III) ion electroreduction increased and shifted towards more positive potentials in the $6 \mathrm{~mol} \mathrm{dm}^{-3}$ chlorate (VII) solutions with the increase in the $\mathrm{NaClO}_{4}$ concentration in the supporting electrolyte, whereas the peaks decreased due to a significantly higher amount of $\mathrm{HClO}_{4}$ in the chlorate (VII) solutions (Fig. 2, curve D). Further increase of $\mathrm{HClO}_{4}$ concentration in the supporting electrolyte solution diminishes the peak height insignificantly and causes its shift towards more negative potentials. For the identical amino acid concentration with the increase of chlorate (VII) concentration from 2 to $6 \mathrm{~mol} \mathrm{dm}^{-3}$, the SWV peak currents of $\mathrm{Bi}(\mathrm{III})$ ion electroreduction increase (Fig. 2a). At the same time, reduction of peak width in the half of their height is observed which evidences the increase in reversibility of $\mathrm{Bi}(\mathrm{III})$ ion electroreduction with water activity drop [14-17]. Also, the picture of DC polarographic waves of $\mathrm{Bi}$ (III) ion electroreduction in the presence of ethionine [21] at all the studied concentrations of chlorates (VII) confirms the increase of electrode process reversibility. 
Table 2 Surface tension $\left(\gamma_{z}\right)$ for $E_{z}$ of chlorate(VII) solutions of concentration ratio $\left(\mathrm{HClO}_{4} / \mathrm{NaClO}_{4}\right)$ : (1:1) solution A, (1:4) solution B, (1:9) solution $\mathrm{C}$, (4:1) solution $\mathrm{D}$, and (9:1) solution $\mathrm{E}+$ ethionine systems

\begin{tabular}{|c|c|c|c|c|}
\hline & \multicolumn{4}{|c|}{$\gamma_{z} / \mathrm{mN} \mathrm{m}^{-1}$} \\
\hline & 0 & $\begin{array}{l}5 \times 10^{4} \mathrm{c}_{\mathrm{E} t} / \\
\mathrm{mol} \mathrm{dm}\end{array}$ & $\begin{array}{l}1 \times 10^{3} \mathrm{c}_{\mathrm{Et}} / \\
\mathrm{mol} \mathrm{dm}\end{array}$ & $\begin{array}{l}3 \times 10^{3} \mathrm{c}_{\mathrm{Et}} \mathrm{t} \\
\mathrm{mol} \mathrm{dm}\end{array}$ \\
\hline \multicolumn{5}{|l|}{$\mathrm{a}$} \\
\hline \multicolumn{5}{|c|}{$2 \mathrm{~mol} \mathrm{dm}^{-3}$ chlorate (VII) } \\
\hline A & 478.81 & 474.09 & 470.42 & 469.51 \\
\hline $\mathrm{B}$ & 470.42 & 470.42 & 469.50 & 465.84 \\
\hline $\mathrm{C}$ & 474.40 & 467.67 & 466.75 & 464.00 \\
\hline $\mathrm{D}$ & 466.33 & 463.08 & 462.17 & 461.25 \\
\hline $\mathrm{E}$ & 470.30 & 466.76 & 465.84 & 465.84 \\
\hline \multicolumn{5}{|l|}{$\mathrm{b}$} \\
\hline \multicolumn{5}{|c|}{$4 \mathrm{~mol} \mathrm{dm}^{-3}$ chlorate (VII) } \\
\hline A & 469.51 & 467.67 & 465.84 & 464.92 \\
\hline $\mathrm{B}$ & 470.33 & 466.75 & 465.84 & 464.00 \\
\hline $\mathrm{C}$ & 474.42 & 470.42 & 466.75 & 463.08 \\
\hline $\mathrm{D}$ & 467.11 & 464.00 & 463.08 & 462.17 \\
\hline $\mathrm{E}$ & 466.31 & 464.92 & 463.08 & 461.25 \\
\hline \multicolumn{5}{|l|}{$\mathrm{c}$} \\
\hline \multicolumn{5}{|c|}{$6 \mathrm{~mol} \mathrm{dm}^{-3}$ chlorate (VII) } \\
\hline A & 471.20 & 464.00 & 462.17 & 461.25 \\
\hline $\mathrm{B}$ & 468.75 & 463.08 & 462.17 & 461.25 \\
\hline $\mathrm{C}$ & 464.65 & 460.33 & 459.42 & 458.50 \\
\hline $\mathrm{D}$ & 466.32 & 459.42 & 458.50 & 457.58 \\
\hline $\mathrm{E}$ & 465.41 & 458.50 & 457.58 & 456.67 \\
\hline
\end{tabular}

The analysis of the cyclic voltammetric curves for the studied systems enables qualitative estimation of the kinetics of $\mathrm{Bi}(\mathrm{III})$ ion electroreduction in the presence of protonated ethionine under the conditions of changeable water activity. The increase in both ethionine [21] and $\mathrm{NaClO}_{4}$ concentrations in the supporting electrolyte results in the decrease of the distance between the anodic and cathodic peaks $\left(\Delta E_{a-c}\right)$ (Fig. 3) in all chlorate (VII) solutions which confirms the increase of reversibility of the $\mathrm{Bi}(\mathrm{III})$ ion electroreduction processes. However, the increase of $\mathrm{HClO}_{4}$ concentration in the chlorate (VII) solution causes reverse dependencies $\Delta E_{a-c}$. With an increase in the concentration of chlorates (VII) from 2 to $6 \mathrm{~mol} \mathrm{dm}^{-3}$ in solutions $\mathrm{A}, \mathrm{B}$, and $\mathrm{C}$ of basic electrolytes, an evident decrease in the $\Delta E_{a-c}$ is observed (Fig. 3a). However, for solutions $\mathrm{D}$ and $\mathrm{E}$ where prevalence of $\mathrm{HClO}_{4}$ increases compared to $\mathrm{NaClO}_{4}$, changes in $\Delta E_{a-c}$ are significantly smaller. The explanation of the observed phenomenon comes from the change of $\mathrm{Bi}(\mathrm{III})$ aqua ion structure which is less hydrated due to the increase of $\mathrm{ClO}_{4}{ }_{4}^{-}$ion concentration. In such form, it is much easier to "reach" the electrode surface [13].

Figure $4 \mathrm{a}, \mathrm{b}$ shows insignificant changes of $\Delta E_{a-c}$ with change of electrode polarization rate in all the studied solutions of basic electrolyte which points out at the chemical reaction $\mathrm{Bi}-\mathrm{Et}$ complex formation controlling the electroreduction rate of $\mathrm{Bi}(\mathrm{III})$ ions [14]. The formation of this complex is favored by the ethionine adsorption on mercury [21]. Therefore, active Bi(III)-ethionine complexes are certainly located inside the adsorptive layer. This was also proved by earlier investigations [14]. The changeable activity of water affects the structure of these complexes and as a result the kinetics of $\mathrm{Bi}(\mathrm{III})$ ion electroreduction process. The obtained values of kinetic parameters based on the DC polarography and cyclic voltammetry measurements indicate the catalytic effect of ethionine, its amount and dependence on changes of protonation and water activity.

As results from Table 3, the introduction of ethionine to the solution of supporting electrolyte causes the shift of $E_{f}^{0}$ towards the more negative potentials. With an increase in the amount of $\mathrm{NaClO}_{4}$ (solutions $\mathrm{A}, \mathrm{B}$, and $\mathrm{C}$ ) in the studied chlorate (VIII) concentrations, an insignificant increase in the $E_{f}^{0}$ value is observed. However, for solutions D and E, the shift of the $E_{f}^{0}$ value towards the more negative potentials takes place which points out at certain chemical changes of the hydrated $\mathrm{Bi}(\mathrm{III})$ ion [20]. 


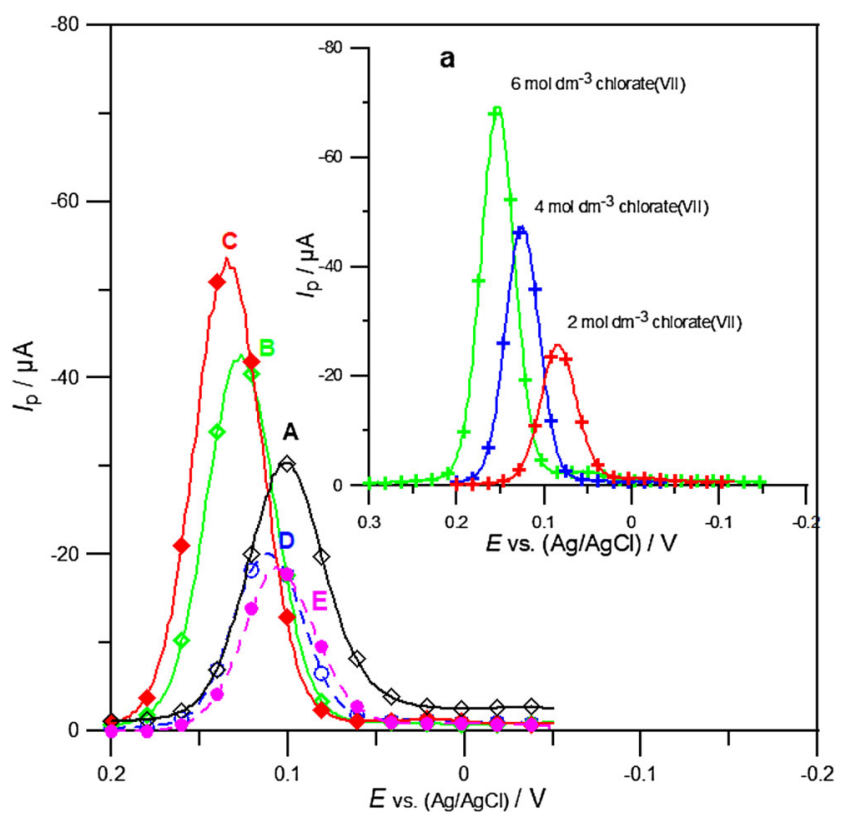

Fig. 2 The SWV peaks of the electroreduction of $1 \cdot 10^{-3} \mathrm{~mol} \mathrm{dm}^{-3} \mathrm{Bi}(\mathrm{III})$ in $6 \mathrm{~mol} \mathrm{dm}^{-3}$ chlorates (VII) in the presence $3 \times 10^{-3} \mathrm{~mol} \mathrm{dm}^{-3}$ ethionine, where $\mathrm{HClO}_{4} / \mathrm{NaClO}_{4}=1: 1$ (white open diamond) $6 \mathrm{~A}$; $\mathrm{HClO}_{4} / \mathrm{NaClO}_{4}=1: 4$ (green open diamond) $6 \mathrm{~B} ; \mathrm{HClO}_{4} / \mathrm{NaClO}_{4}=1: 9$ (red filled diamond) $6 \mathrm{C} ; \mathrm{HClO}_{4} / \mathrm{NaClO}_{4}=4: 1$ (blue open circle and blue broken line) $6 \mathrm{D} ; \mathrm{HClO}_{4} / \mathrm{NaClO}_{4}=9: 1$ (pink filled circle and pink broken line) $6 \mathrm{E}$. a The SWV peaks of the electroreduction of $1 \times$ $10^{-3} \mathrm{~mol} \mathrm{dm}^{-3} \mathrm{Bi}(\mathrm{III})$ in $2 \mathrm{~mol} \mathrm{dm}^{-3}$ chlorate (VII) (red cross), $4 \mathrm{~mol} \mathrm{dm}^{-3}$ chlorate (VII) (blue cross), and $6 \mathrm{~mol} \mathrm{dm}^{-3}$ chlorate (VII) (green cross) with $3 \times 10^{-3} \mathrm{~mol} \mathrm{dm}{ }^{-3}$ ethionine, where $\mathrm{HClO}_{4} / \mathrm{NaClO}_{4}=$ $1: 4$

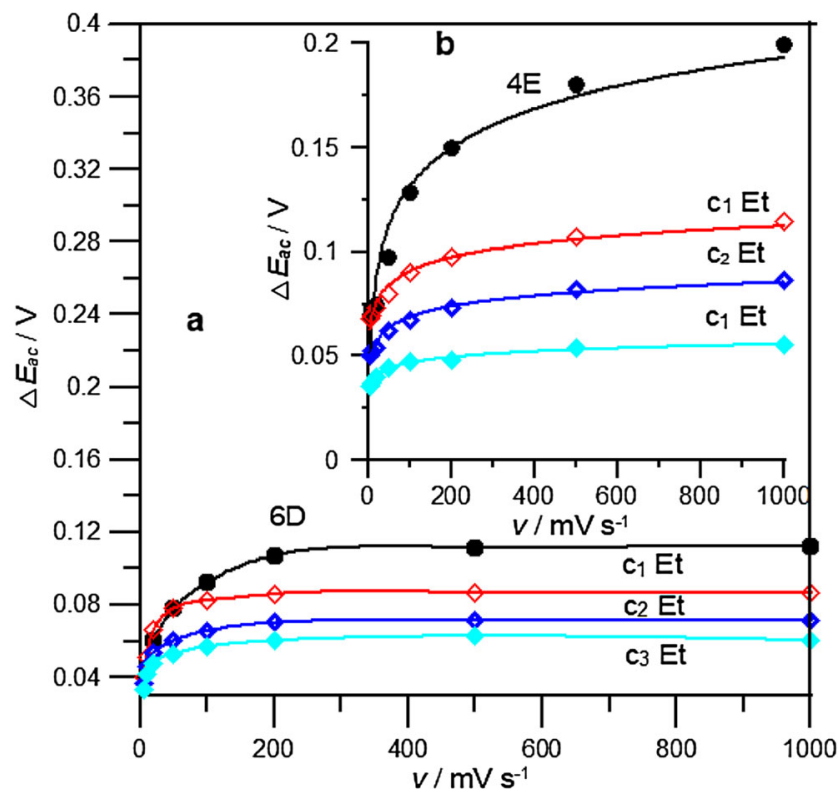

Fig. 4 The influence of polarization rate on the difference between the potentials of the anodic and cathodic peaks $\Delta E_{a-c}$ for the $\mathrm{Bi}(\mathrm{III}) / \mathrm{Bi}(\mathrm{Hg})$ couple in $6 \mathrm{~mol} \mathrm{dm}^{-3}$ chlorates (VII), where $\mathrm{HClO}_{4} / \mathrm{NaClO}_{4}=4: 1$ (black filled circle) $6 \mathrm{D}$ (a) and in $4 \mathrm{~mol} \mathrm{dm}{ }^{-3}$ chlorates (VII), where $\mathrm{HClO}_{4} /$ $\mathrm{NaClO}_{4}=9: 1$ (black filled circle) $4 \mathrm{E}(\mathbf{b})$ and in the presence of $5 \times$ $10^{-4} \mathrm{~mol} \mathrm{dm}^{-3}$ (red clear diamond), $1 \times 10^{-3} \mathrm{~mol} \mathrm{dm}^{-3}$ (blue clear diamond), $3 \times 10^{-3} \mathrm{~mol} \mathrm{dm}^{-3}$ (sky blue filled diamond) ethionine

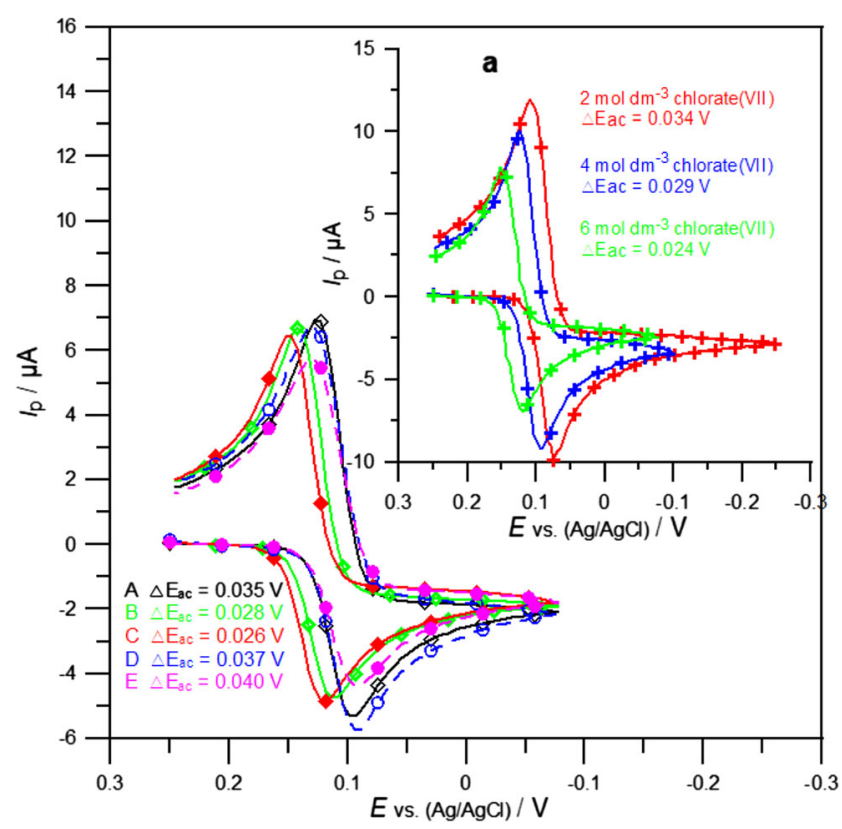

Fig. 3 The cyclic voltammograms of $1 \times 10^{-3} \mathrm{~mol} \mathrm{dm}^{-3} \mathrm{Bi}(\mathrm{III})$ in $4 \mathrm{~mol} \mathrm{dm}{ }^{-3}$ chlorates(VII) in the presence $3 \times 10^{-3} \mathrm{~mol} \mathrm{dm}^{-3}$ ethionine, where $\mathrm{HClO}_{4} / \mathrm{NaClO}_{4}=1: 1$ (white open diamond) $4 \mathrm{~A} ; \mathrm{HClO}_{4} /$ $\mathrm{NaClO}_{4}=1: 4$ (green open diamond) 4B; $\mathrm{HClO}_{4} / \mathrm{NaClO}_{4}=1: 9$ (red filled diamond) $4 \mathrm{C} ; \mathrm{HClO}_{4} / \mathrm{NaClO}_{4}=4: 1$ (blue open circle and blue broken line) $4 \mathrm{D} ; \mathrm{HClO}_{4} / \mathrm{NaClO}_{4}=9: 1$ (pink filled circle and pink broken line) 4E. a The cyclic voltammograms of $1 \times 10^{-3} \mathrm{~mol} \mathrm{dm}^{-3}$ Bi(III) in $2 \mathrm{~mol} \mathrm{dm}^{-3}$ chlorate (VII) (red cross), $4 \mathrm{~mol} \mathrm{dm}^{-3}$ chlorate (VII) (blue cross), and $6 \mathrm{~mol} \mathrm{dm}^{-3}$ chlorate (VII) (green cross) with $3 \times$ $10^{-3} \mathrm{~mol} \mathrm{dm}{ }^{-3}$ ethionine, where $\mathrm{HClO}_{4} / \mathrm{NaClO}_{4}=1: 9$

An increase in the value of cathodic transition coefficients $\alpha$ after the introduction of ethionine in all electrolyte solutions indicates an increase in reversibility of the $\mathrm{Bi}(\mathrm{III})$ ion electroreduction. It should be noted that an increase in the concentrations of $\mathrm{NaClO}_{4}$ in the supporting electrolyte solution (especially in the solutions with low water activity) causes that the values of transition coefficients $\alpha$ change insignificantly. However, in the solutions with a prevailing concentration of chloric(VII) acid (solutions D and E), the coefficient values decrease considerably.

According to Petrii et al. [31], such changes of $\alpha$ coefficient values indicate an asymmetry of intermolecular reorganization change and the coefficient arbitrary asymmetry factor $\nu<<1$ for zero overvoltage $\eta=0$. It can be assumed that for the reduction of $\mathrm{Bi}-\mathrm{Et}(\alpha \sim 0.55-0.70)$, the electrons transfer to the antibonding molecular orbital of the complex reactants and the inner-sphere rearrangement occur [32].

The correlation of the standard rate constants $k_{s}$ (for comparison determined based on the CV and EIS measurements) with water activity (Table 3 ) shows that both water activity and the presence of the amino acid protonated to a different extent influence the $\mathrm{Bi}$ (III) ion electroreduction rate. The $k_{s}$ values indicate that the catalytic action of ethionine increase in the following order $\mathrm{A}<\mathrm{B}<\mathrm{C}$ for chlorates (VII) (Table 2). However, for the $\mathrm{D}$ and $\mathrm{E}$ solutions (of the dominant amount of $\mathrm{HClO}_{4}$ acid), 


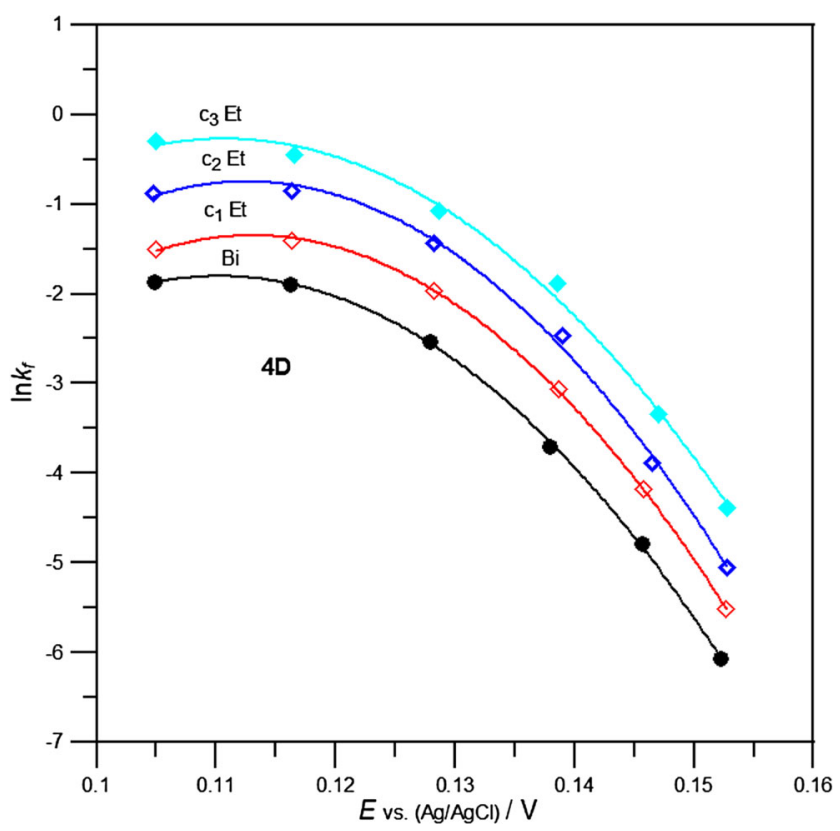

Fig. 5 Dependence of the rate constants of $1 \times 10^{-3} \mathrm{~mol} \mathrm{dm}^{-3} \mathrm{Bi}(\mathrm{III})$ electroreduction in $4 \mathrm{~mol} \mathrm{dm}^{-3}$ chlorates (VII), where $\mathrm{HClO}_{4} /$ $\mathrm{NaClO}_{4}=4: 1$ (black filled circle) $6 \mathrm{D}$ in the presence of $5 \times$ $10^{-4} \mathrm{~mol} \mathrm{dm}^{-3}$ (red open diamond), $1 \times 10^{-3} \mathrm{~mol} \mathrm{dm}{ }^{-3}$ (blue open diamond), and $3 \times 10^{-3} \mathrm{~mol} \mathrm{dm}^{-3}$ (sky blue filled diamond) ethionine on the electrode potential

an evident drop of ethionine catalytic activity is observed. It should be noted that the largest catalytic activity is observed

Table 3 The values of formal potentials $\left(E_{f}^{0}\right)$, cathodic transition coefficients $(\alpha)$, standard rate constants $\left(k_{s}\right)$ of electroreduction of $1 \times 10^{-3} \mathrm{~mol} \mathrm{dm}{ }^{-3} \mathrm{Bi}$ (III) in chlorate (VII) solutions of concentration for the chlorate (VII) solutions of large water activity, with the decrease when water activity decreases gradually. The increase in $\mathrm{ClO}_{4}^{-}$ion concentration results in the destruction of water structure, making ethionine adsorption easier. This leads to the assumption that though adsorption of the catalyzing substance is a necessary condition to accelerate the electrode process, according to the cap-pair rule [11], it does not decide about the catalytic effect size. This should be associated with the reaction equilibrium of the active complex formation, as well as their composition [11, 19-21].

The nonlinearity of $\ln k_{f}=f(E)$ (Fig. 5) points out at the multi-stage process of $\mathrm{Bi}(\mathrm{III})$ ion electroreduction in the presence of ethionine in all tested chlorate solutions(VII) [7, 11, 33]. Moreover, the influence of catalytic substance on the first electron transfer is usually much stronger than on the other electron transfers.

\section{Conclusions}

Based on the results of the presented studies, there can be drawn the following conclusions:

- Specific adsorption of differently protonated ethionine proceeds through the sulfur atom directed towards the mercury surface.

ratio $\left(\mathrm{HClO}_{4} / \mathrm{NaClO}_{4}\right)$ : (1:1) solution $\mathrm{A},(1: 4)$ solution $\mathrm{B},(1: 9)$ solution C, (4:1) solution $\mathrm{D},(9: 1)$ solution $\mathrm{E}$ [20] and in the presence $3 \times 10^{-3} \mathrm{~mol} \mathrm{dm}^{-3}$ ethionine

\begin{tabular}{|c|c|c|c|c|c|c|c|}
\hline \multirow[t]{2}{*}{ Chlorate (VII) } & \multicolumn{2}{|l|}{$E_{f}^{0} / \mathrm{V}$} & \multicolumn{2}{|l|}{$\alpha$} & \multicolumn{3}{|c|}{$10^{3} \mathrm{k}_{s} / \mathrm{cm} \mathrm{s}^{-1}$} \\
\hline & $\mathrm{Bi}(\mathrm{III})$ & $\mathrm{Bi}(\mathrm{III})+\mathrm{Et}$ & $\mathrm{Bi}(\mathrm{III})$ & $\mathrm{Bi}(\mathrm{III})+\mathrm{Et}$ & $\mathrm{Bi}(\mathrm{III})$ & $\mathrm{Bi}(\mathrm{III})+\mathrm{Et}(\mathrm{CV})$ & $\mathrm{Bi}(\mathrm{III})+\mathrm{Et}(\mathrm{EIS})$ \\
\hline \multicolumn{8}{|c|}{$2 \mathrm{~mol} \mathrm{~mol}^{-3}$ chlorate (VII) } \\
\hline A & 0.102 & 0.082 & 0.28 & 0.53 & 0.143 & 5.35 & 5.51 \\
\hline B & 0.097 & 0.085 & 0.33 & 0.60 & 0.150 & 7.39 & 8.25 \\
\hline $\mathrm{C}$ & 0.095 & 0.088 & 0.35 & 0.66 & 0.152 & 9.62 & 14.00 \\
\hline $\mathrm{D}$ & 0.098 & 0.086 & 0.31 & 0.46 & 0.152 & 3.07 & 2.94 \\
\hline $\mathrm{E}$ & 0.102 & 0.083 & 0.27 & 0.42 & 0.128 & 2.32 & 1.82 \\
\hline \multicolumn{8}{|c|}{$4 \mathrm{~mol} \mathrm{~mol}^{-3}$ chlorate (VII) } \\
\hline $\mathrm{A}$ & 0.125 & 0.123 & 0.40 & 0.60 & 2.44 & 11.70 & 11.70 \\
\hline B & 0.131 & 0.125 & 0.41 & 0.61 & 1.35 & 12.90 & 16.90 \\
\hline $\mathrm{C}$ & 0.125 & 0.126 & 0.40 & 0.66 & 1.24 & 15.20 & 27.70 \\
\hline $\mathrm{D}$ & 0.111 & 0.108 & 0.39 & 0.60 & 1.04 & 8.53 & 8.09 \\
\hline E & 0.110 & 0.105 & 0.39 & 0.88 & 0.713 & 6.13 & 8.00 \\
\hline \multicolumn{8}{|c|}{$6 \mathrm{~mol} \mathrm{~mol}^{-3}$ chlorate (VII) } \\
\hline A & 0.150 & 0.150 & 0.70 & 0.75 & 6.17 & 8.63 & 9.81 \\
\hline $\mathrm{B}$ & 0.157 & 0.154 & 0.60 & 0.77 & 4.66 & 17.10 & 20.10 \\
\hline $\mathrm{C}$ & 0.158 & 0.158 & 0.54 & 0.78 & 2.71 & 18.10 & 23.80 \\
\hline $\mathrm{D}$ & 0.143 & 0.145 & 0.40 & 0.64 & 1.09 & 6.66 & 8.73 \\
\hline $\mathrm{E}$ & 0.140 & 0.145 & 0.39 & 0.56 & 0.691 & 6.13 & 8.61 \\
\hline
\end{tabular}


- With the increasing concentration of the supporting electrolyte, the ethionine adsorption properties increase which is associated with the destructive effect of $\mathrm{ClO}_{4}{ }^{-}$ ions on the water structure and greater accessibility of amino acid to the electrode surface.

- Changes in the ethionine protonation degree in the studied chlorate (VII) solution indicate the reorganization of amino acid molecules on the electrode surface.

- $\quad$ The kinetics of Bi(III) electroreduction in chlorates (VII) with varying water activities is affected by the presence of ethionine and changes in the protonation of this amino acid.

- The relationships of $\mathrm{Bi}(\mathrm{III})$ electroreduction rate constants as a function of the electrode potential (lack of linearity) indicate that in the presence of the catalyzing substance, the electrode process takes place in stages.

- The multistep $\mathrm{Bi}(\mathrm{III})$ electroreduction process is controlled by the kinetics of the formation of active complexes on the electrode surface.

- The largest catalytic activity is observed for the chlorate (VII) solutions of great water activity.

- The size of the catalytic effect is connected with the equilibrium of the reaction of creating active complexes before successive transition of electrons.

- According to the Marcus theory [7, 11], the composition of active complexes after subsequent electron transfers is changed, which results from change in the solvatation shell of the ion after a partial loss of charge.

Open Access This article is distributed under the terms of the Creative Commons Attribution 4.0 International License (http:// creativecommons.org/licenses/by/4.0/), which permits unrestricted use, distribution, and reproduction in any medium, provided you give appropriate credit to the original author(s) and the source, provide a link to the Creative Commons license, and indicate if changes were made.

\section{References}

1. R. Kalvoda, Chem. Anal. 52, 869 (2007)

2. J. Barek, Port. Electrochim. Acta 31, 291 (2013)

3. J. Nieszporek, J. Electroanal. Chem. 706, 108 (2013)
4. A. Perek-Dlugosz, A. Socha, J. Rynkowski, Electrocatalysis 8, 270 (2017)

5. O. Ikeda, K. Watanabe, Y. Taniguchi, H. Tamura, Bull. Chem. Soc. Jpn. 57, 3363 (1984)

6. G. Dalmata, A. Nosal-Wiercińska, T. Zięcina, Collect. Czechoslov. Chem. Commun. 69, 267 (2004)

7. G. Dalmata, Electroanalysis 17, 789 (2005)

8. J. Nieszporek, D. Gugała-Fekner, D. Sieńko, J. Saba, K. Nieszporek, Collect. Czechoslov. Chem. Commun. 73, 616 (2008)

9. F.G. Bănică, D. Guziejewski, S. Skrzypek, W. Ciesielski, D. Kazimierczak, Electroanalysis 21, 1711 (2009)

10. A. Nosal-Wiercińska, Cent. Europ. J. Chem. 8, 1 (2010)

11. A. Nosal-Wiercińska, Electroanalysis 26, 1013 (2014)

12. M. Wiśniewska, K. Szewczuk-Karpisz, D. Sternik, J. Therm. Anal. Cal. 120, 1355 (2015)

13. A. Nosal-Wiercińska, Electrochim. Acta 55, 5917 (2010)

14. A. Nosal-Wiercińska, J. Electroanal. Chem. 654, 66 (2011)

15. A. Nosal-Wiercińska, J. Electroanal. Chem. 662, 298 (2011)

16. A. Nosal-Wiercińska, J. Electroanal. Chem. 681, 103 (2012)

17. A. Nosal-Wiercińska, Electrochim. Acta 92, 397 (2013)

18. A. Nosal-Wiercińska, M. Grochowski, M. Wiśniewska, K. Tyszczuk-Rotko, S. Skrzypek, M. Brycht, D. Guziejewski, Electrocatalysis 6, 315 (2015)

19. M. Grochowski, A. Nosal-Wiercińska, M. Wiśniewska, A. Szabelska, B. Goł biowska, Electrochim. Acta 207, 48 (2016)

20. M. Grochowski, A. Nosal-Wiercińska, J. Electroanal. Chem. 788, 198 (2017)

21. A. Nosal-Wiercińska, M. Grochowski, Electrocatalysis 8, 492 (2017)

22. M. Wiśniewska, A. Nosal-Wiercińska, I. Dąbrowska, K. Szewczuk-Karpisz, Micropor. Mesopor. Mat. 175, 92 (2013)

23. I. Ostolska, M. Wiśniewska, Appl. Surf. Sci. 311, 734 (2014)

24. T. Klepka, Polymers 53, 390 (2008)

25. T. Klepka, H. Dębski, H. Rydarowski, Polymers 54, 668 (2009)

26. J.F. Read, K.J. MacCormick, A.M. McBain, Transit. Met. Chem. 29, 149 (2004)

27. S. Ishii, M. Hirane, S. Kato, N. Fukushima, T. Tsujiuchi, Biochem. Biophys. Res. Commun. 456(135), 135 (2015)

28. A. Nosal-Wiercińska, G. Dalmata, Electroanalysis 22, 2081 (2010)

29. A. Nosal, M.G. Wiercińska, Collect. Czechoslov. Chem. Commun. 76, 265 (2011)

30. L. Bandura, M. Franus, R. Panek, A. Woszuk, W. Franus, Przem. Chem. 94, 323 (2015)

31. O.A. Petrii, R.R. Nazmutdinov, M.D. Bronshtein, G.A. Tsirlina, Electrochim. Acta 52, 3493 (2007)

32. M.D. Bronshtein, R.R. Nazmutdinov, W. Schmickler, Chem. Phys. Lett. 399, 307 (2004)

33. J. Nieszporek, Electroanalysis 24, 1584 (2012) 